\title{
Intergenerational linkages in consumption patterns and the geographical distribution of surnames
}

\author{
M. Dolores Collado ${ }^{a}$, Ignacio Ortuño-Ortín b,*, Andrés Romeu
}

a Universidad de Alicante, Spain

Universidad Carlos III, Spain

Eniversidad de Murcia, Spain

\begin{tabular}{ll}
\hline & A B S T R A C T \\
& $\begin{array}{l}\text { This paper attempts to detect the existence of links in consumption patterns between generations. Preferences } \\
\text { over consumption goods may be determined by the preferences of parents and/or by preferences arising from } \\
\text { the environment. We propose an indirect methodology to overcome the lack of data on consumption choices } \\
\text { of dynasties, i.e., parents and their adult offspring. This new approach is based on the analysis of the correlation } \\
\text { between the geographical distributions of surnames and consumption choices. We show that there is no signifi } \\
\text { cant intergenerational link on consumption patterns for non food goods. Our results also suggest that there is a link } \\
\text { between parents' and children's preferences over food items. }\end{array}$ \\
\hline JEL classification: & D12
\end{tabular}

Keywords:

Preference formation

Migration

Surnames

Geographical consumption patterns

Mantel test

\section{Introduction}

A central theme in the study of preference formation is the relative influence of parents versus the influence of the social environment in shaping a person's preferences. Thus, preference formation can be un derstood as emerging from a preference transmission from parents to offspring, and a preference transmission between any two individ uals. The influence coming from parents is sometimes called "vertical transmission" and the influence from other people is called "horizon tal transmission." ${ }^{1}$ Vertical transmission of preferences can take place

\footnotetext{
We specially thank Luis Ubeda for his very useful suggestions and comments. We also thank Klaus Desmet, Jaime Kahhat, Javier Ruiz-Castillo, Christian Schultz and two anonymous referees. A previous version of this paper, entitled "Vertical transmission of consumption behavior and the distribution of surnames" was presented at The Econometric Society World Conference, London 2005, The European Economic Association Meeting, Amsterdam 2005, and in seminars at Universidad Carlos III, Universitat Pompeu Fabra, UAB and CEMFI. Authors gratefully acknowledge financial support from the Spanish MEC through grants ECO2008-05721, ECO2011-29751, ECO 2010-19596 and ECO2010-19830. Romeu also acknowledges financial support from Fundación SENECA 11998.

* Corresponding author at: Departament of Economics, Universidad Carlos III de Madrid, C/ Madrid 126, 28903-Getafe, Madrid, Spain.

E-mail address: iortuno@eco.uc3m.es (I. Ortuño-Ortín).

This terminology is based on Cavalli-Sforza and Feldman (1981) (see also Bisin and
} verdier, 2001 . through children's imitation of their parents' tastes or through the parents' teaching of certain habits and values (and perhaps through some genetic inheritance). Horizontal transmission occurs when chil dren adopt the habits of other agents outside the household, as for ex ample when they learn values or preferences taught in school or when they imitate friends.

This paper provides a novel empirical approach to assess the impor tance of the parental and the environmental influence on the formation of children's preferences over consumption goods. Namely, we study the transmission of the rates of substitution for consumption goods as when a child adopts his parents' strong taste for eating meat rather than being vegetarian. However, we neither seek to describe the precise working of those channels of preference transmission nor attempt to provide any new theoretical explanation on the issue of preference for mation. The paper just provides an empirical framework for detecting whether there is a significant intergenerational link on preferences over consumption goods.

Since preferences are not observable we will have to use data on consumption behavior instead. It will be argued that, after controlling for income and other variables that may affect consumption decisions, a correlation on the preferences of parents and their offspring implies a correlation on the consumption bundles chosen by parents and the consumption bundles chosen by their (adult) offspring. If there were data available on those consumption choices, assessing the significance of an intergenerational link would be an easy task. Unfortunately, unlike 
other types of intergenerational transmission, such as earnings or abili ties, we are not aware of the existence of any survey that provides such information on a large number of consumption goods.

Thus, we propose an indirect strategy to overcome the data prob lem: we will compare the spatial distribution of consumption be havior and the spatial distribution of surnames. By studying whether regions with similar surname distributions also have simi lar expenditure patterns, we will be able to draw some conclusions on the effect of parental versus environmental transmission of preferences.

The intuition behind this approach is simple: if parental transmis sion is very strong, preferences are transmitted from parents to chil dren in a similar way to surnames. Consider an economy composed by geographical regions that originally were quite different in both the distribution of surnames and the distribution of consumption pat terns. Suppose that there have been important recent migration flows among the regions. If parental transmission is perfect, so that sur names and preferences are transmitted in the same way, regions that have experienced large migration flows should be close both in the distribution of surnames and in the distribution of expenditure patterns. In contrast, if environmental transmission of preferences is the main force in the preference formation process, surnames and preferences evolve in different manner and regions that have experi enced more migration flows will have more similar surnames distri butions but not more similar consumption patterns. Thus, we will be able to detect intergenerational links by studying the spatial distri butions of surnames and consumption patterns in different regions. More specifically, we will construct two matrices of distances be tween regions. The first matrix will be computed by calculating the distances in consumption patterns between regions and the second matrix by computing the distances in the distribution of surnames between regions. It will be argued that if parental transmission plays a significant role, after controlling for other relevant variables, those two matrices should be positively correlated. Unfortunately, there still remains an identification problem since a positive correla tion need not imply parental transmission of preferences. If natives of the host region adopt the preferences of immigrants the two matri ces would be positively correlated but this would be due to an envi ronmental transmission of preferences. However, the case of no correlation between the two matrices will unambiguously indicate a strong environmental transmission effect. Moreover, the weaker the linkage between parent's preferences and children's preferences the faster immigrants adapt to their host societies. Thus, the analysis of the correlation of such matrices will enable us to draw some insights on both the general issue of preference formation and the more specific question on immigrant integration. Modern economies expe rience large migration flows. Research on the mechanism of assimila tion of immigrants is important not only from a welfare point of view, but also to predict future trends in demand and consumption patterns.

It might happen that the correlation between the matrix of sur names distances and the matrix of consumption patterns is explained by other variables unrelated to the paternal/environment effect that we want to study here. For example, it might happen that geograph ically closer provinces have similar surnames distributions and are also similar in the type of local agricultural produce available. The type of rural/urban environment might also condition consumption patterns because prices and the availability of certain goods depend on it. Thus, we will control for other factors that may have some ex planatory power in the correlation between the two matrices. In par ticular, we will control for geographical distance, how urban/rural regions are, income differences, climate and household composition.

Using data from Spain, the paper shows that for non food items there is no significant linkage between parents' preferences and those of their offspring. Regarding food consumption the paper sug gests, but cannot unequivocally prove, that preferences are partially inherited from the parents. This result also suggests that in Spain, sec ond generation immigrants adopt the consumption patterns of the host region for all goods except for food items.

An alternative explanation of our result for food items could be based on the household production model of Stigler and Becker (1977). Under such model we would be detecting transmission of skills in the household production of food related goods rather than transmission of preferences. Even though this distinction between preferences and technology could be seen as "a matter of semantics, not substance" (Pollak, 1978, page 375), we repeat our analysis differ entiating between food items that are clearly cooking inputs and food items that are typically eaten without being further processed. In both cases we obtain again a positive correlation between the matrix of consumption distances and the matrix of surnames distances.

The statistical tool used to assess the possible correlation between distances in the distribution of surnames and distances in the distri bution of consumption patterns is the multivariate Mantel Test, a method for testing (linear) correlation between distance matrices. The Mantel test has been applied to problems of Spatial Autocorrela tion in Ecology and in Population Genetics (see Mantel, 1967; Sokal and Rohlf, 1995; Legendre and Legendre, 1998). However, to the best of our knowledge, this is the first time that this test has been ap plied in Economics (see Desmet et al., 2009 for another recent appli cation in Economics).

In this paper we use data from Spain, although the approach is general and the data needed is also available for many other coun tries. There are several reasons why Spain is an excellent case study. First, there were large internal migration flows in the last century. ${ }^{2}$ Second, the number of foreign immigrants in Spain until the late 90s was very low compared to other countries. This is important be cause having a very high number of foreign immigrants would sub stantially complicate the analysis, as it would be necessary to have information on consumption patterns from the immigrants' countries of origin. Third, information on surnames is easily available as a com puter database file using the telephone directory in electronic format. Fourth, the Spanish surveys on household consumption are of high quality as documented in Browning and Collado (2001). Finally, the regions considered are relatively small areas and therefore, we have a significant number of observations, and representative data are available at such aggregation level.

There is an extensive literature dealing with intergenerational cor relations in, for example, income (Solon, 1992; Mazumder, 2005), wealth (Charles and Hurst, 2003) abilities and aggregated consump tion (Mulligan, 1999), IQ (Daniels et al., 1977; Feldman et al., 2000), political orientation (Jennings et al., 2001), generosity (Wilhelm et al., 2008) intertemporal preferences (Becker and Mulligan, 1997), altruistic preferences (Mulligan, 1997), contributions to public goods (Cipriani et al., 2007), and risk and trust attitudes (Dohmen et al., forthcoming). Waldkirch et al. (2004) deals with the type of intergenerational correlation considered in this paper. They study the intergenerational transmission of consumption preferences using data from the PSID that contain information on the total food expenditure of parents and of their adult offspring. They are the first to investigate potential intergenerational correlation in con sumption beyond that induced through an intergenerational trans mission of permanent income. After controlling for income and other relevant variables, they find a significant intergenerational transmission on tastes for food. Unfortunately their data set does not provide more disaggregated information on consumption choices that is the sort of information required to analyze intergenerational transmission of preferences over consumption bundles. Our paper contributes to this literature since we analyze intergenerational

\footnotetext{
${ }^{2}$ In year $196018 \%$ of the Spanish citizens were living in a different region from the one where they were born. For years 1970, 1981 and 1991 the corresponding percentages were 22.6, 23.5 and 22.4 respectively (Carreras and Tafunell, 2005).
} 
links between parents' and children's preferences over a disaggre gated set of consumption goods. We find that parental transmission of preferences affects the shares of the different food products rather than the total amount spent on food. Simonson and Sela (2011) using a twins study find a heritable effect on preferences for certain prod ucts. However, the sample size is very small and the number of con sumer goods analyzed is quite limited.

The distribution of surnames in the population has been used to analyze several issues in areas such as Population Genetics and Health Sciences. This is because it contains relevant information about geo graphical mobility and the mating structure in a society. Since there are links between surnames and genotypes, scientists working in Population Genetics have incorporated the distribution of surnames into the analysis of population genetic diversity (Lasker, 1985; Jobling, 2001). In Health Science, surnames can be useful in studying the relationship between levels of inbreeding and prevalence of cer tain types of tumor and other diseases of genetic origin (see for exam ple Holloway and Sofaer, 1992).

In Economics, the study of surnames has been mostly applied in the analysis of very specific discrimination and social integration problems and on questions of social mobility (see for example Einav and Yariv, 2006; Fryer and Levitt, 2004; Goldin and Shim, 2004; Collado et al., 2008; Clark, 2009, 2010) but not in issues of interge nerational transmission of preferences. One possible reason why the information contained in surnames and its distribution has not been more intensively exploited in the literature could be the fact that, until very recently, large data sets were not available in electronic for mat. However, things have changed dramatically in the last few years, and in most developed countries telephone directories on CD ROM support are now easily available and contain information about basi cally all households. ${ }^{3}$

\section{Consumption preferences and surnames distribution}

Our goal is to assess the possible correlations between the prefer ences of parents and children. The paper, however, does not look at the specific channel of preference transmission from parents to chil dren, and it is compatible with the possibility that children mimic particular consumption behavior of parents and/or that consumption behavior is attributed to genetic inheritance (see Rowe (1994) and Harris (1998) for the view that parental influence on child outcomes is limited, Cesarini et al. (2009) for the view that preferences for giv ing and risk taking are broadly heritable and Simonson and Sela (2011) for a heritable effect on preferences for certain products). Since we do not observe preferences such possible correlation cannot be estimated directly. One possible approach to overcome this prob lem is to analyze the correlation between the consumption vectors of parents and their children. A correlation between preferences should, controlling for prices and income, be associated with a correlation on consumption vectors, i.e., parental transmission of preferences should imply an intergenerational link in consumption patterns.

Unfortunately, and contrary to the cases of transmission of earn ings or abilities, except for some very limited surveys on consumption of specific goods, there are no good data available on the consump tion vector of parents and their (adult) offspring to check for such possible intergenerational link in consumption. Therefore, we follow an indirect approach in order to detect the existence of parental transmission. This approach is based on assessing how surnames and consumption patterns are distributed across different geographi cal regions of the country using a measure of geographical dissimilar ity. The key idea is that surnames remain unaltered when transmitted

\footnotetext{
${ }^{3}$ In some countries, such as the UK, there are other comprehensive sources available e.g. national census and electoral registers. However, in most countries the access for researchers to these data is restricted due to privacy concerns.
}

vertically across generations, while consumption patterns may be de termined by environmental and/or parental transmission.

An example might help to clarify the central idea of this paper. Consider two regions, $A$ and $B$, and let $w_{I}$ be the mean consumption vector and $x_{I}$ the vector of surname frequencies of agents in region $I$ $(I=A, B)$. Let $d(\cdot)$ be a distance measure in the space of consumption patterns and surname frequencies. Assume that at a certain period in time regions $A$ and $B$ do not share any surname in common, so that if the $j^{\text {th }}$ element of $x_{A}$ is zero the same element of $x_{B}$ is not zero and vice versa. ${ }^{4}$ Suppose that individual preferences are very different across regions, and therefore, consumption patterns are also very different. ${ }^{5}$ These two assumptions imply that both $d\left(w_{A}, w_{B}\right)$ and $d\left(y_{A}, y_{B}\right)$ are large. Suppose that a representative agent moves from $A$ to $B$ and has a child born in $B$. In the next period the old agent dies and his child becomes an adult and stays in $B$. What are the implications of this migration in terms of $d\left(w_{A}, w_{B}\right)$ and $d\left(x_{A}, x_{B}\right)$ ? The distance in surnames, $d\left(x_{A}, x_{B}\right)$ will decrease since the child bears a surname that did not exist in region $B$ before. However, the distance in con sumption $d\left(w_{A}, w_{B}\right)$ will decrease or remain constant depending on the importance of parental transmission. Under full parental trans mission the child of the immigrant consumes the same vector as his father and this implies that $d\left(w_{A}, w_{B}\right)$ will also decline. This reasoning shows that, under full parental transmission, migration implies a de crease in surname and consumption distances. ${ }^{6}$ Therefore, regions that are close in terms of surnames should also be close in terms of consumption patterns. This implies a positive correlation between consumption distances and surname distances. In the event that pa rental transmission plays no role and the child of the immigrant ac quires the preferences of region $B$, the distance $d\left(w_{A}, w_{B}\right)$ would remain constant. However, the children of the natives might also ac quire the preferences of the immigrants and, in this case, the dis tance $d\left(w_{A}, w_{B}\right)$ would decrease. Therefore, horizontal transmission might imply both zero or positive correlation be tween surnames and consumption distances. Thus, a positive corre lation between distances in surnames and distances in consumption is a necessary but not sufficient condition for parental transmission.

We will construct a matrix of surname distances and a matrix of consumption distances between the regions of mainland Spain. Based on the idea above, we claim that parental transmission should be reflected in a positive and significant correlation between these two matrices.

\section{Data on surnames and consumption}

\subsection{Surname distribution in Spain}

We consider the geographical surname distribution in Spain in 1999 extracted from the telephone directory. The directory can be purchased in a CD ROM distributed for commercial purposes (INFO BEL, http://www.infobel.com). The directory contains 11.5 million domestic users and provides information on the full name and ad dress of the subscriber, including the address and the zip code. ${ }^{7}$ The

\footnotetext{
${ }^{4}$ This is an extreme assumption, it is only required that the distribution of surnames differs substantially among regions.

${ }^{5}$ We are implicitly assuming that prices are the same in both regions and all agents have the same income.

${ }^{6}$ The reasoning above is just an example. In principle, migration between two regions with different distributions of surnames does not always reduce the distance in surnames. For example, suppose that in period 1 surname " $x$ " only exists in region A and in period 2 all the people with such surname migrate to region $\mathrm{B}$ and nobody else migrates. In this case the distance in surnames between the two regions might remain the same in both periods. To rule out that possibility we need to assume that migration is not surname biased i.e., that there is no selection by surnames. Using the same reasoning we also have to assume that migration is not consumption biased.

7 To the best of our knowledge this is the first paper using the information on the surnames of all the telephone users in Spain and not just a sample of them.
} 
total population of Spain in 1999 was around 40 million and the total number of main family residences was around 14 million. As men tioned in the introduction, the number of foreign immigrants in Spain until the late 90 s was very low compared to other countries. Even in 1999, the number of foreign residents was $1.4 \%$ of the total population compared to $6.1 \%$ in France and $8.8 \%$ in Germany (see OECD, 2002). Furthermore, because there have been no significant foreign migration inflows in the modern history of Spain the sur names analyzed here are largely of Spanish ancestry.

The naming convention in Spain is different from most Western countries, and similar to that prevailing in some Latin American countries. The main distinctive feature is that the family name is formed by two surnames, the first being the father's first surname and the second the mother's first surname. ${ }^{8}$ A second important fea ture is that married women keep their maiden surname and do not adopt the husband's surname. This convention was legally estab lished after the introduction of the Civil Registry in 1870 but it had been followed by a very large majority of the population since much earlier (see Salazar Acha, 1991; Fauré et al., 2001 for a History of sur names in Spain). Thus, for at least four or five generations the first surname of a person is the first surname of his/her father. ${ }^{9}$ This is im portant because it allows us to conclude that population movements from one region to another permanently reduce the surname differ ences between the two regions.

Even though the telephone directory is possibly the best source available it has some problems: first, there may be duplicity of some surnames as an individual may have several telephone lines in differ ent residences. Second, there is a potential bias towards people living in urban areas. Finally, some surnames have alternative spellings (e.g. Giménez and Jiménez) and it is difficult to decide which surnames are variant spellings and which are different surnames. Most variant spel lings diverged many generations ago and thus we treat different spel lings as different genealogical lines. Furthermore, the computer file on the CD ROM records the paternal and maternal surname in a sin gle field and in some cases it is difficult to disentangle the first from the second, particularly when compound names are involved. To overcome this problem, we use a computer program that implements an algorithm to separate the first (paternal) and the second (mater nal) surname as accurately as possible ${ }^{10}$ and we use only the first sur name in our analysis. However, all the results in the paper remain unchanged if we either use the second surname instead of the first one, or if we pool together the first and second surnames.

Spain is divided into 52 districts called provinces. This geographi cal division was formally set in 1833 and in most cases followed the dominions of Medieval kingdoms, principalities and bishoprics, thus grouping people with a historically common institutional linkage. In this paper we only consider the 47 provinces in the Iberian Peninsula, leaving out the territories of the Canary archipelago, the Balearic Islands, and the two autonomous cities in the North of Africa, Ceuta and Melilla. The telephone directory provides the zip code of each user that is a much smaller area than the province. Even though a smaller geographical division leads to a bigger sample size, we will consider the province as the geographical unit of reference since the other data sources that we need are available only at provincial level.

\footnotetext{
${ }^{8}$ There have been some changes in naming conventions during the past decades. The law now allows for changes in the order of the surnames. This practice, however, is rather unusual and responds to personal motivations, for instance preserving the mother's surname in the next-to-present generation.

9 There is one exception to this general rule. The law allows the combination of the two surnames of a person into a new one to be passed on to their offspring. However, this possible merger of surnames is not immediate and the total number of such double-barrelled surnames is very low (see Collado et al., 2008).

${ }^{10}$ The program was coded in Q-BASIC and is available upon request. Our algorithm drops $3.1 \%$ of the total population. This includes foreign residents who have just one surname.
}

Provinces are of similar geographical extension, though the popu lation varies widely, ranging from Madrid with around 5.5 million in habitants to Soria with just 95,000. Provinces are quite heterogeneous in population density and urban concentration, what made us con cerned that the telephone directory might be over sampling predom inantly urban provinces compared to those with dispersed rural populations. However, for all provinces, the number of individuals in cluded in the telephone directory corresponds to approximately $30 \%$ of the population of each province ${ }^{11}$ so we observe no particular bias towards under sampling in rural provinces.

We found 132,882 different surnames in the whole country. The most common surname is García (3.5\% of the population) and there are almost 60,000 surnames borne by just a single person. The 40 most common surnames cover $32.7 \%$ of the population, a figure higher than the $13.1 \%$ reported by Clark (2009) for England and Wales. We found that the number of family names of the same size (the size of a family name is number of people bearing this surname) follows approximately a power law distribution with parameter -1.7 , that is in accordance with the empirical findings for other countries and the theoretical pre dictions reported in Derrida et al. (1999, 2000). The most common sur names are German and Latin patronymics (Fernandez, Rodriguez, Martinez,...), geographic names (Navarro, Serrano,...), and names from personal characteristics (Blanco, Delgado,...). According to Rodriguez Larralde et al. (2003) occupational names (Molina, Herrero,...) occur less frequent than in other European populations, and Arab surnames (Medina, Alcantara,...) are only relatively frequent in Andalusia.

\subsection{Surname distances}

Our goal here is to construct a matrix of surnames distances among the Spanish provinces using the data from the telephone book described in the previous Section. We denote by $x_{i}$ the relative (national) frequency of surname $i$ and by $x$ the vector of such (nation al) frequencies. Similarly, we denote by $x_{i}^{j}$ the relative frequency of surname $i$ in province $j$ and by $x^{j}$ the vector of such frequencies in province $j$. We construct a matrix of surname distances between the provinces that is denoted by $D .{ }^{12}$ The $(j, k)$ element of the $D$ matrix represents the distance between province $j$ and province $k$ and is given by

$$
d_{j k} \quad\left(\sum_{i=1}^{N}\left|x_{i}^{j}-x_{i}^{k}\right|^{p}\right)^{\frac{1}{p}}
$$

where $N$ is the total number of different surnames in Spain (i.e., $N=132,882$ ) and $p \geq 1$. We choose the Manhattan distance, ${ }^{13}$ i.e. $p$ equal to 1 , because is the only one among the distances defined in (1) satisfying the following desirable "anonymity" property: Consider two provinces $A$ and $B$ and assume migration from A to $B$. If this movement of population contributes to reduce (increase) the sur name distance between the two provinces, the reduction (increase) in the distance is the same regardless of the surnames borne by the migrants.

Spain has experienced low immigration rates until very recently, therefore, matrix $D$ can be thought to contain aggregate information on the amount of interior migration flows (between provinces) over the last few centuries. Using this matrix we find that the average distance between provinces is 1.22 . Notice the maximum value the

\footnotetext{
11 The $\mathrm{R}^{2}$ of the OLS regression is 0.98 .

12 This matrix and all the other matrices calculated in the paper, as well as the software programs used for the computation of correlation tests, are available from the authors upon request.

${ }^{13}$ We have checked that all the results in this paper are robust to choice of $p$.Namely, we have repeated all our calculations for $p=2,5,10,100$ and the limiting case when $p \rightarrow \infty$, obtaining very similar results.
} 
Manhattan distance can take is 2 , therefore, this result indicates that there are substantial differences in the surname distribution across provinces. The largest distance is 1.67 between Lugo and Huesca, two provinces far apart that have had very different historical ties, and the shortest distance is 0.52 between Seville and Cádiz that are next to each other and are considered very close from a historic and sociological point of view. As expected, closer provinces tend to have more similar surnames and the correlation between geographi cal and surname distances between provinces is 0.44 . Despite this high average distance between provinces, the Spanish population is relatively uniform when compared to other European populations and, for example, the most common surnames in the country are also the most common surnames in most provinces (see Rodriguez Larralde et al., 2003). We calculate the "center of gravity", i.e., the province that minimizes the distance to all the other provinces weighted by the population. We find that the primary center of grav ity lies with Madrid, followed by Barcelona, i.e., the two major prov inces in terms of population.

\subsection{Consumption expenditure}

In this section, we construct an aggregated consumption vector for each province that will be used to compute a matrix of "preference distances" between provinces. Preferences are unobservable but con sumption is not. Individuals choose their consumption profiles by maximizing their preferences subject to their corresponding budget restrictions. One option would be to use standard econometric re gression methods to estimate the unknown parameters of the Engel curves that correspond to the unknown parameters of the individual preferences. However, we think that to pick up parental transmission of preferences it is very important to use a highly disaggregated clas sification of goods. Therefore, it would be unfeasible to estimate an Engel curve for each good considered in our analysis. For this reason, we use the raw vector of consumption shares to define a distance ma trix. We are aware that variability in these shares responds not only to differences in preferences across provinces but also to heterogene ity in real prices, income and other factors. We control for these fac tors in the empirical analysis.

We calculate budget shares for each province using the 1990/91 consumer expenditure survey (Encuesta de Presupuestos Familiares, EPF). The EPFs are large surveys conducted every ten years by the Spanish National Statistics Office (Instituto Nacional de Estadística, INE). These surveys use a representative sample of the Spanish popu lation by province, providing very detailed information on household expenditure. They are used by officials to calculate consumption weights in the Consumer Price Index (IPC). In 1997 the EPF was replaced by the continuous consumer expenditure survey (Encuesta Continua de Presupuestos Familiares, ECPF) that uses a smaller sam pling design and it is not representative at the provincial level. Thus, the EPF 1990/91 was the last large survey that is representative at provincial level, with a sample size of 21,155 households. We con sider one hundred and ten composite goods that correspond to the subclasses defined by the Spanish Statistics Office. The description of the subclasses is listed in the Appendix A.

We calculate the budget share of good $i$ in province $j$ as

$$
\mathrm{w}_{i}^{j} \frac{\sum_{h \in \text { province } j} c_{i h}}{\sum_{h \in \text { province } j} c_{h}}
$$

where $c_{i h}$ is the amount expended on good $i$ by household $h$, and $c_{h}$ is total expenditure by household $h$. Let $w^{j}$ denote the vector of budget shares for province $j$.
As we did in the case of surname frequencies, we now define the distance in consumption shares between province $j$ and province $k$ as

$s_{j k} \quad \sum_{i=1}^{110}\left|w_{i}^{j}-w_{i}^{k}\right|$

The matrix of preference distances between provinces is denoted by $S$ and contains the distance $s_{j k}$ as the $(j, k)$ element.

Before proceeding, one might claim that the matrix $S$ is not capturing the differences in preferences between populations in the provinces for at least two reasons:

1. Our vector of budget shares, $w_{l}^{i}$, is an aggregated measure and some relevant information may be shaded by the way we aggregate.

2. As already claimed, consumption shares do not depend only on pref erences but also on prices, income and other types of differences, such as weather, or the proportion of urban/rural population.

Regarding the aggregation problem, there is not much we can do since aggregating always implies a loss of information. Still, one could claim that the specific way used to compute the vector $w_{i}^{j}$ is not satisfactory and averaging over individual budget shares might be more desirable. This alternative, however, was not adopted due to the problem of infrequency of purchases of durable goods. In any case, we compute the average budget shares for each province using only food expenditures ${ }^{14}$ to avoid the durable goods problem, and the correlation between the corresponding distance matrix and the $S$ matrix calculated with food goods is 0.966 . Hence, both matrices contain essentially the same information and using one or the other would not affect our results.

In principle, the second problem raised could be solved by incor porating the necessary information on those variables. However, this is not an easy task since some of the required information, partic ularly about prices, is not available so that alternative and feasible ap proaches to reduce the severity of the problem have to be pursued. In our case, the following strategy is adopted:

- To reduce the problem of consumers facing different prices in dif ferent provinces we drop expenditures on housing from our analy sis. Real estate prices vary widely across provinces and represent a very large component of the budget. Thus, we eliminate seven sub classes ${ }^{15}$ from the calculations, leaving 103 consumption items. Furthermore, it is expected that the law of one price applies for tradable goods, while significant price differences between regions could appear for non tradable goods. For this reason we perform a robustness check distinguishing between tradable and non tradable goods. We also control for the distance between provinces as a proxy for transportation costs.

- We control for differences in income across provinces as well as other factors such as the proportion of urban/rural population and differences in climate and household composition.

Thus, our matrix $S$ contains information on the distances between provinces on the aggregated vector of relative expenditures for 103 different consumption goods. Using this matrix we find that the aver age distance between provinces is 0.28 , the largest distance is 0.46 and the shortest is 0.14 . Since, as we mention above, the maximum value the Manhattan distance can take is 2 , the differences in the dis tribution of consumption patterns across provinces are economically important. We interpret those distances as representing the con sumption preference distances between provinces.

\footnotetext{
${ }^{14}$ Food expenditures are divided into thirty-three subclasses ranging from subclass 110 -A to 120 -A (see Table 3).

15 Subclasses 310-A to 320-B (see Table 3). Our main results do not depend on the exclusion of these subclasses.
} 


\section{Main results}

\subsection{A first test}

In this Section we test whether there is a positive correlation be tween the distance in terms of consumption shares and in terms of surname frequencies. We indeed find a positive correlation that sug gests the existence of a significant parental transmission effect.

We ask the following question: Is there a statistically significant positive correlation between the matrix $D$ and the matrix $S$ ? This seems a priori an easy question to answer. There is, however, a " tech nical" problem: Since the elements of a distance matrix are not inde pendent $^{16}$ we cannot use standard methods of least square estimation. To overcome this problem we use the Mantel test that is specially designed for testing linear correlation between distance ma trices. The Mantel test is a non parametric randomization procedure that can be used to test any linear relationship but is especially useful in the case of non independent data points. The Mantel's test statistic is the correlation coefficient, $r$, of the distance matrices $D$ and $S$, and its value range is $[-1,1]$.The significance of the correlation is evalu ated via random permutation of the rows and corresponding columns of $D$ and $S$. For each random permutation, the correlation $r$ is comput ed. After a sufficient number of iterations, ${ }^{17}$ the distribution of values of $r$ is generated and the critical value of the test at the chosen level of significance is found from this distribution.

In our case, we find that the correlation coefficient between matri ces $D$ and $S$ is 0.4198 and the hypothesis of non positive correlation is strongly rejected on the basis of a Mantel test with 10, 000 replica tions ( $\mathrm{p}$ value zero). Tables 1 and 2 in the Appendix A contain this and subsequent results. ${ }^{18}$ Thus, we conclude that closer provinces in terms of surnames also tend to be closer in terms of preferences.

One might say that this result is not surprising at all and it only de tects those provinces that have had much mixing one with another have similar preferences and similar surnames. Though this effect is clear for surnames, it is not obvious that population mixing should lead to more similar preferences as this depends on the attitudes of the newcomers (or locals) with respect to their new environment and their willingness to assimilate the values of the host region. Fur thermore, it is even less obvious that provinces with similar prefer ences should have experienced intense population mixing. It might well be the case that two populations have similar preferences as a consequence of the spread of certain cultural and social views through channels that do not require population mixing. ${ }^{19}$ Thus, we should control for other factors that may have some explanatory power in the correlation found between matrix $D$ and matrix $S$.

\subsection{Controlling for other variables}

So far, we have considered a simple correlation between surname distances and preference distances. In this Section we show that such correlation also holds after controlling for some relevant variables. This result is considered as a check of the robustness of the signifi cance of the parental transmission effect on consumption behavior.

As we mention above, it is clear that the correlation between ma trix $D$ and matrix $S$ might depend on a number of different facts that include:

- Geographical distance between provinces

- How urban/rural provinces are

\footnotetext{
${ }^{16}$ This is due to the triangle inequality property.

17 The number of iterations for all the runs in this article was 10,000.

18 All our results are robust to the exclusion of the most common surnames or the very rare ones.

${ }^{19}$ This is somewhat similar to an old question in Population Genetics about the demic versus the cultural transmission of technological changes. See Cavalli-Sforza et al. (1994) and Jobling et al. (2004).
}

- Income differences

- Climate

- Household composition

\subsubsection{Geographical distance}

The geographical distance between provinces accounts for trans portation costs and could also be very closely correlated with other variables, for example the type of local agricultural produce available, that might explain some of the differences in consumption. Thus, we will define the matrix of geographical distances between provinces, $G$, where the element $g_{j k}$ indicates the distance, in kilometers, between the capital of province $j$ and the capital of province $k$. Since provinces are relatively small in area and in most cases the majority of the pop ulation is concentrated around the provincial capital, this distance is a good index of the geographical distance between the whole popula tions in the provinces.

\subsubsection{Urban/rural}

It is natural to assume that consumption shares in urban environ ments might differ from consumption shares in rural areas, even if household preferences were identical, as urban and rural households face different prices and the set of available goods may be different. In order to control for this, we classify municipalities into eight groups ${ }^{20}$ and assign each household in the EPF sample to the corresponding group. We denote by $u_{i}^{j}$ the percentage of households in group size $i$ in province $j$. Then the "urban" distance between province $j$ and prov ince $k$ is given by

$u_{j k} \quad \sum_{i=1}^{8}\left|u_{i}^{j}-u_{i}^{k}\right|$

and the corresponding matrix of distances is denoted by $U$.

\subsubsection{Income}

The EPF contains information on the total income reported by household members. In principle, this information could be used to control for the income effect. However, since this variable is provided by the survey respondent herself, it is natural to suspect of under reporting. For this reason we decided to use total expenditure instead. Total expenditure is highly correlated with household income and it does not suffer from significant measurement error. Thus, denoting by $m^{j}$ the mean household total expenditures in province $j$, the "in come" distance between province $j$ and province $k$ is given by $m_{j k}=\left|m^{j}-m^{k}\right|$ and the corresponding matrix is denoted by $M$.

\subsubsection{Climate}

The weather in Spain varies greatly across regions. In general, the North is cold and rainy and the South warm and dry. Because of these differences, people with the same preferences might need to consume different goods depending on their province of residence. To control for this a matrix of "climate distances," $T$, is defined in the following way: for each province $j$ we compute the vector $t^{j}=\left(t_{1}^{j}, \ldots, t_{12}^{j}\right)$, where the $t_{i}^{i}$ element indicates the average temperature ${ }^{21}$ during month $i$. The climate distance between province $j$ and $k$ is given by

$$
t_{j k} \sum_{i=1}^{12}\left|t_{i}^{\mathrm{j}}-t_{i}^{k}\right|
$$

and the matrix $T$ is formed with these elements.

\footnotetext{
${ }^{20}$ Groups are defined in terms of population intervals: 2,000 or less, from 2,000 to 5,000 , from 5,000 to 10,000 , from 10,000 to 20,000 , from 20,000 to 50,000 , from 50,000 to 100,000 , from 100,000 to 500,000 and more than 500,000 .

${ }^{21}$ These temperatures are averages for 1997-2002. These data are available from the website of the Spanish Statistics Office, http://www.ine.es/.
} 


\subsubsection{Household composition}

Finally, household composition may be a major explanatory factor in determining differences in consumption patterns. Rural provinces contain a higher proportion of elderly, retired people, whose con sumption pattern differs substantially from that of a middle aged family with children, for instance. The EPF also contains information on household composition in the form of a categorical variable for the fourteen different types of households. In Table 4 in the Appendix A we describe the different type of household defined in the EPF. We compute the vector $h^{j}$ for province $j$ containing the pro portion of households of each type. Thus, matrix $H$ denotes the dis tances in terms of household composition.

Summing up, we have the matrices $S, D, G, U, M, T$ and $H$, the dis tance matrices of, respectively, consumption shares, surnames, geo graphical distances, proportion of urban/rural population, income per capita, climate and household composition. The question now is how to extend the bivariate Mantel test to our context of multiple control variables. Smouse et al. (1986) propose the following three step technique:

- OLS estimation of $D$ on $G, U, M, T$ and $H$

- OLS estimation of $S$ on $G, U, M, T$ and $H$

- Bivariate Mantel test using the residuals of the previous two regressions.

Therefore, we perform a multivariate Mantel test to determine the significance of the correlation coefficient of the $D$ and $S$ matrices, con trolling for $G, U, M, T$ and $H$. The correlation is now 0.2277 and is sig nificantly greater than zero as the p value is 0.0042 . Thus, after controlling for how close provinces are in income, urban/rural envi ronment, geographical distance, climate and household composition, we still find that provinces that are similar in the frequencies of sur names tend to be similar in their consumption preferences.

\subsection{Different groups of consumption goods}

We now look at differences in the correlation depending on the type of consumption good considered. Parental transmission might play a more important role in, for example, the formation of prefer ences over food than in the formation of other types of preferences. Or, equivalently, for some types of consumption good such as food, the offspring of immigrants can be less prompted to adopt the habits of the host province than for other consumption goods. This new ex ercise will also help to analyze whether the positive correlation be tween surname and consumption distances is due to what we call a ghetto grouping effect. If immigrants tend to concentrate into some particular areas, newcomers will be living in the same environment as in their province of origin. In this case, the preferences of the par ent would coincide with those of the environment, and therefore, we should find a large correlation coefficient for all consumption goods both under parental and environmental transmission.

We create two new distance matrices in consumption shares. The first matrix, $S_{f}$, includes exclusively all food goods that are the first thirty three items on the list used to compute $S .{ }^{22}$ The second ma trix, $S_{n f}$, contains the remaining seventy items. Then we repeat our previous multivariate Mantel test twice, firstly replacing matrix $S$ by matrix $S_{f}$ and secondly replacing $S$ by $S_{n f}$. The results of these two tests indicate a striking difference between food and non food cases. The test for food items (matrix $S_{f}$ ) shows a significant correla tion coefficient of 0.3735 ( $\mathrm{p}$ value 0 ). The correlation coefficient when the matrix with non food items, $S_{n f}$, is used is 0.0465 and non significant ( $\mathrm{p}$ value 0.3190 ).

\footnotetext{
22 Subclasses 110 -A to $120-\mathrm{A}$ in Table 3.
}

The non significance of this coefficient indicates that newcomers assimilate the preferences of locals in non food consumption. This fact is difficult to interpret under the assumption of "ghetto grouping" and no parental transmission. Thus, our findings on the correlation coefficients are more consistent with the following statement: there is full environmental transmission on preferences over the non food consumption goods, and therefore perfect integration of immigrants to their host environment. Regarding preferences over food items the results show lack of integration and suggests, but cannot unam biguously conclude, the existence of a strong parental transmission effect. $^{23}$

This possible parental transmission for food preferences is related to the results provided in Waldkirch et al. (2004). It is important to notice that these authors provide a result on possible parental trans mission for the total amount spent on food. Our analysis, however, is much more disaggregated and focuses on the expenditure shares of thirty three different food items. Moreover, after controlling for the State of residence of parents and their offspring they obtain no corre lation in the total amount spent on food. Interestingly, we have checked and found that a similar result holds in our case, i.e. after controlling for income and geographical distance the total amount spent on food is not related to surname distances. Thus, our findings also suggest that parental transmission of preferences affects the shares of the different food products rather than the total amount spent on food.

Three additional comments are called for here. First, it may be that our test does not detect parental transmission for non food goods be cause the classification of these goods is less disaggregated than the classification of food goods. For example, it might be the case that chil dren have the same preferences as parents for going to the theatre in stead of to the cinema. However, both theatre and cinema expenditure belong to the same category and therefore the transmission of this sort of preference cannot be detected with our data. We have repeated all the previous tests using the maximum level of disaggregation avail able in the EPF (246 food items and 523 non food items) and the re sults remain unchanged. ${ }^{24}$ Second, our result could be due to the fact that preferences for non food goods are basically the same across provinces. Our data, however, do not support this view since the non food consumption patterns are different across the Spanish prov inces even after controlling for income, geographical distance, house hold composition and climate (the unexplained variability of the regression is 79.2\%). Third, following the approach in Stigler and Becker (1977) an alternative explanation of our result for food goods is that we are not detecting transmission of preferences but transmission of skills in the household production of food related goods. Cooking is a production process that is learnt within the family environment and children and young adults might easily acquire their parents' cooking skills or "human capital". Since parents and their off spring share similar cooking skills it is natural to expect them to buy similar "cooking inputs" as well, i.e. similar food, and this fact is reflected in a similar composition of their food consumption shares. Although we cannot perfectly discriminate between this "skill trans mission" hypothesis and our "preference transmission" hypothesis, we tried to shed some light on this issue by dividing food items in two groups and running separate regressions. The first group includes food items that are clearly cooking inputs, like salt, sugar, vinegar, rice, flour, eggs, butter, different types of oil, of milk, of pasta, of meat, of

\footnotetext{
${ }^{23}$ This ambiguity derives from the discussion in Section 1.2 where we have shown that a positive correlation between surnames and consumption distances is a necessary but not sufficient condition for parental transmission.

24 The results of these tests and the detailed specifications are available upon request The disaggregated list of EPF goods and services can be found in http://www.ine.es/
} 
fish, of fresh vegetables, etc. The second group includes food items that are typically eaten without being further processed, like coffee, tea, chocolate, ice creams, different types of fresh fruits, of bread, of pas tries, of ham and sausages, of cheese, etc. ${ }^{25}$ We find a positive and sig nificant correlation coefficient for both groups (see columns 1 and 2 in Table 2). The correlation coefficients are 0.3168 ( $p$ value 0 ) for the first group and 0.3698 ( $p$ value 0 ) for the second. This result does not rule out the "skill transmission" hypothesis but shows that it is not the unique channel. Finally, the main caveat of our approach is that we cannot perfectly control for differences in prices across prov inces. We control for how urban/rural regions are which partially ex plains differences in prices. We also control for geographical distance that accounts for transportation costs for tradable goods. However, for non tradable goods there might be differences in prices between provinces that we have not accounted for, and these differ ences in prices could be driving our results for non food goods because, although we have exclude housing from the analysis, non food goods include some non tradable services that could have differ ent prices in different provinces. To check whether our results for non food goods are driven by differences in prices, we have calculated our correlations for non food goods using only tradable goods (see col umn 3 in Table 2). Tradable non food goods include books, magazines, towels, blankets, carpets, cutlery, jewelry, computers, different types of clothes, of furniture, of small appliances, of cleaning products, of toiletries, of vehicles, of toys, etc. ${ }^{26}$ The correlation coefficient for trad able goods is 0.1389 ( $p$ value 0.1 ), a bit larger than for all non food items but still non significant. This result confirms that the absence of correlation for non food items is not driven by differences in prices across provinces.

\subsection{Controlling for recent migration}

In this Section we show that controlling for recent migration flows does not alter the finding of the previous Section. Thus, the possible importance of parental transmission only for food consumption re mains true even when we leave out recent migrants.

One might claim that immigrants' adaptation to their host envi ronment takes place during the second generation (see Borjas, 1994). In this case, since there were some significant migration flows in Spain in the 60s and 70s, our previous conclusion relating a significant correlation coefficient as a necessary condition for a paren tal transmission effect might be misleading. To see this, suppose that the first generation of adult immigrants keep their original prefer ences. Their offspring, however, adopt the preferences of the host province, i.e. environmental transmission is the only factor in the preference formation process. However, the matrix of surname dis tances and the matrix of consumption shares could be correlated be cause of the recent migration, leading us wrongly to deduce the possibility of a significant parental transmission.

To control for this possibility we should disentangle the contribu tion of recent migration to the consumption and surname vectors and this requires information on the net migration flows between Spanish provinces during the last generation. Unfortunately, this information is not available. However, the Spanish labor force survey (Encuesta de la Poblacion Activa, EPA) also conducted by the INE, contains infor mation on the current province of residence and the birthplace of in dividuals. The EPA is a quarterly survey and the sample size is around 190,000 individuals. Households are interviewed for six consecutive

quarters. In this study we merge two waves of the EPA: First quarter 1999 and third quarter $2000 .{ }^{27}$ Thus, using the data from the EPA, we construct a matrix, $E$, of "migration" distances in the following way: we associate the vector $b^{j}=\left(b_{1}^{j}, \ldots, b_{47}^{j}\right)$ to province $j$ such that the $b_{i}^{j}$ element contains the percentage of people living in province $j$ who were born in province $i$. We construct the matrix $E$ in a similar way to the previous matrices. The element $e_{j k}$ is the distance between province $j$ and $k$, i.e. $e_{j k} \quad \sum_{i}^{47}\left|b_{i}^{j}-b_{i}^{k}\right|$. Since geographical mobility over the last 15 years in Spain has been very low we are confident that a large majority of the people born in province $i$ and currently living in province $j$ did not live in another province before migrating to $j$. Thus, our matrix $E$ may be seen as a good approximation to the matrix of recent migration flows between Spanish provinces.

We repeat our previous multivariate Mantel test now including the additional matrix $E$. More precisely, we test the significance of the correlation coefficient between matrix $S$ and matrix $D$, controlling for $G, U, M, T, H$ and $E$. We obtain that the correlation coefficient is 0.1669 (see Table 1 ), lower than before but still large and significant ( $p$ value 0.0359 ). We also carry out the test when consumption goods are divided into food (matrix $S_{f}$ ) and non food groups (matrix $S_{n f}$ ) as in the previous subsection. It is reassuring to observe that the correlation coefficient when only food is considered is still high (0.3154) and significant ( $p$ value 0.0002), and the coefficient for the non food case remains low (0.0180) and clearly non significant ( $p$ value 0.4191 ), indicating that for non food goods parental trans mission plays no role in the preference formation process.

We were concerned that the significance of our results were due to a small number of "outlier" provinces. Hence, we have checked the ro bustness of our test by sequentially dropping groups of three provinces. Then, we run the test for all possible subsets of provinces (16.215) leav ing out one triplet in each run. The results show that when we consider all goods we find a non significant correlation in about one third of the runs. In the case of food consumption the correlation coefficient in all the runs is positive and significant at the $5 \%$ level. For non food items the correlation coefficient is not significantly greater than zero at the $5 \%$ level in any of the runs. Hence, we are confident that our results are not driven by a small number of extreme observations.

We also checked that the results presented in the previous section regarding cooking inputs and tradable non food goods remain valid after controlling for recent immigration (see Table 2).

\section{Final comments and further work}

We have developed a novel indirect approach to analyze the exis tence of intergenerational linkages in consumption preferences. This new approach is based on the analysis of the correlation between the geographical distributions of surnames and consumption choices. It is important to stress here that the use of surnames, though novel in this field, is not indispensable to our method: the spatial distribution of any other individual characteristic that is perfectly transmitted from parents to offspring could play the same role. However, surnames fit perfectly for this purpose and by using the spatial distribution of sur names obtained from the telephone directory we have shown that only for food items there might be an intergenerational linkage.

Information on geographical distribution of surnames is becoming easily available for many other countries where there are also good surveys of consumption behavior. Applying our methodology to a second country would be an important exercise in investigating the robustness of our results and making international comparisons.

\footnotetext{
${ }^{25}$ The grouping is based on the detailed classification that considers 246 food items. The detailed list of goods on each group is available upon request.

${ }^{26}$ The classification into tradable and non-tradable is based on the detailed classification that considers 523 non-food items. The detailed list of tradable goods is available upon request.
}

${ }^{27}$ We use these two waves to avoid duplicity of households. 
Appendix A. Tables

Table 1

Mantel Test Statistics.

\begin{tabular}{llll}
\hline Control variables. & All EPF & Food & Non Food \\
\hline None & 0.4198 & 0.5391 & 0.1991 \\
& $(0.0000)$ & $(0.0000)$ & $(0.0089)$ \\
Urban, income, climate, Kms, household & 0.2277 & 0.3735 & 0.0465 \\
composition & $(0.0042)$ & $(0.0000)$ & $(0.3190)$ \\
Urban, income, climate, Kms, household & 0.1669 & 0.3154 & 0.0180 \\
composition, recent immigration & $(0.0359)$ & $(0.0002)$ & $(0.4191)$ \\
\hline
\end{tabular}

Right tail p-values in parenthesis.

Table 2

Mantel Test Statistics.

\begin{tabular}{llll}
\hline Control variables. & $\begin{array}{l}\text { Cooking } \\
\text { inputs }\end{array}$ & $\begin{array}{l}\text { Other } \\
\text { food } \\
\text { goods }\end{array}$ & $\begin{array}{l}\text { Non food } \\
\text { (tradable } \\
\text { goods) }\end{array}$ \\
\hline None & 0.5393 & 0.5730 & 0.2005 \\
& $(0.0000)$ & $(0.0000)$ & $(0.0136)$ \\
Urban, income, climate, Kms, household & 0.3168 & 0.3698 & 0.1389 \\
composition & $(0.0000)$ & $(0.0000)$ & $(0.1000)$ \\
Urban, income, climate, Kms, household & 0.2404 & 0.3141 & 0.0599 \\
composition, recent immigration & $(0.0006)$ & $(0.0002)$ & $(0.2995)$ \\
\hline
\end{tabular}

Right tail p-values in parenthesis.

Table 3

Subclasses of consumption goods in the EPF survey.

Class Subclass

110 A. Rice B. Flour and lightly processed cereals C. Bread D. Pastry-cooked products E. Pasta products and other cereal based products

111 A. Beef B. Veal C. Pork D. Sheep meat

E. Poultry F. Cooked pork G. Canned and processed meat

$H$. Other meats and meat offal

112 A. Fresh and frozen fish B. Dried, smoked, canned and processed fish C. Fresh and frozen crustaceans and molluscs

113 A. Liquid milk B. Preserved milk C. Cheese and other dairy products D. Eggs

114 A. Butter and margarine B. Edible oils

115 A. Fresh fruit B. Nuts and raisins, olives, canned fruit and fruit juices C. Fresh vegetables D. Dried vegetables E. Frozen, preserved and canned vegetables

116 A. Potatoes and their by-products

117 A. Sugar

118 A. Coffee, cocoa, infusions and substitutes

119 A. Chocolate and chocolate substitutes B. Other food products

120 A. Non-alcoholic beverages

130 A. Spirits B. Wine C. Beer D. Other alcoholic beverages

140 A. Tobacco

210 A. Men's clothes B. Men's underwear C. Women's clothes

D. Women's underwear E. Children's clothes

F. Children's and babies' underwear G. Clothing complements and repairs

220 A. Men's footwear B. Women's footwear C. Children's and babies' footwea

221 A. Footwear repair

310 A. Housing rentals B. Expenses related to property

C. Repair and maintenance of rented housing D. Repair and maintenance of property

311 A. Water supply

320 A. Electricity and gas B. Heating fuels

410 A. Furniture for kitchen and bathroom B. Other furniture and decorative ornaments for the household $\mathrm{C}$. Floor coverings and repairs

420 A. Household textiles B. Other furniture goods and repairs

430 A. Refrigerators, washing machines, dishwashers and irons B. Cookers

C. Heating appliances D. Other electrical appliances and repairs

440 A. Glassware, tableware, cutlery and their repairs

B. Other kitchen and household equipment and their repairs

450 A. Goods for cleaning and routine household maintenance

B. Other non-durable household goods

451 A. Household services, except domestic service

460 A. Domestic service
Table 3 (continued)

\begin{tabular}{ll}
\hline Class & Subclass \\
\hline 510 & A. Medical products B. Other pharmaceutical products \\
520 & A. Therapeutic appliances and equipment and repairs \\
530 & A. Medical, nursing and other out-patient services \\
540 & A. Hospital services and similar \\
550 & A. Health insurance \\
610 & A. Motor cars B. Other vehicles \\
620 & A. Tyres, spare parts and repairs \\
621 & A. Fuels and lubricants \\
622 & A. Other goods related to personal transport \\
630 & A. Local transport \\
631 & A. Long-distance transport \\
640 & A. Postal services and communications \\
710 & A. Radio and television equipment and repairs B. Other audio-visual \\
& equipment \\
711 & A. Photographic equipment, computers and others \\
712 & A. Equipment for sport B. Games and toys C. Other recreational goods \\
720 & A. Cinema, theatre, football and others performances \\
721 & A. Recreational services \\
730 & A. Books newspapers and magazines \\
740 & A. Pre-primary and primary education B. Secondary education \\
& C. Expenses related to education D. Secondary education \\
810 & E. Education not definable by level \\
811 & A. Personal care services \\
820 & A. Jewellery, imitation jewellery and their repairs \\
821 & A. Other personal effects \\
822 & A. Stationery materials \\
830 & A. Restaurants, bars and cafes \\
831 & A. Hotels and other accommodations \\
840 & A. Tourist services \\
850 & A. Financial services \\
860 & A. Other services \\
&
\end{tabular}

Table 4

Type of household considered

\begin{tabular}{ll}
\hline Column & Type of household \\
\hline 1 & One adult aged 65 or older without children \\
2 & One adult younger than 65 without children \\
3 & One adult with one or more children \\
4 & Couple without children (head aged 65 or older) \\
5 & Couple without children (head younger than 65) \\
6 & Couple with one child \\
7 & Couple with two children \\
8 & Other households with two adults (wihtout children) \\
9 & Other households with two adults \\
10 & Three adults (without children) \\
11 & Three adults (with children) \\
12 & Four adults or more (without children) \\
13 & Four adults or more (with children) \\
\hline
\end{tabular}

\section{References}

Becker, G.S., Mulligan, C.B., 1997. The endogenous determination of time preference. Quarterly Journal of Economics 112, 729-758.

Bisin, A., Verdier, T., 2001. The economics of cultural transmission and the dynamics of preferences. Journal of Economic Theory 97, 298-319.

Borjas, G., 1994. Long-run convergence of ethnic skill differentials: the children and grandchildren of the great migrations. Industrial \& Labor Relations Review 47, 553-573.

Browning, Martin, Collado, M. Dolores, 2001. The response of expenditures to anticipated income changes: panel data estimates. American Economic Review 91, 681-692.

Cavalli-Sforza, L.L., Feldman, M.W., 1981. Cultural Transmission and Evolution: A Quantitative Approach. Princeton University Press, Princeton.

Cavalli-Sforza, L.L., Menozzi, P., Piazza, A., 1994. The History and Geography of Humans Genes. Princeton University Press, Princeton.

Carreras, A., Tafunell, X., 2005. Estadí sticas históricas de España. Bilbao: Fundación BBVA, eds.

Cesarini, D., Dawes, C.T., Johannesson, M., Lichtenstein, P., Wallace, B., 2009. Genetic variation in preferences for giving and risk taking. Quarterly Journal of Economics 809-842 May.

Charles, K.K., Hurst, E., 2003. The correlation of wealth across generations. Journal of Political Economy 111 (6), 1155-1182.

Cipriani, M., Giuliani, P., Jeanne, O., 2007. Like mother like son? Experimental evidence on the transmission of values from parents to children. IZA Discussion Paper $n$. 2768. 
Clark, Gregory, 2009. The indicted and the wealthy: Surnames, reproductive success, genetic selection and social class in pre-industrial England. mimeo.

Clark, Gregory, 2010. Regression to mediocrity? Surnames and social mobility in England, 1200-2009. mimeo.

Collado, M.D., Ortuño-Ortin, I., Romeu, A., 2008. Surnames and social status in Spain. Investigaciones Economicas 32 (3), 259-287.

Daniels, M., Devlin, B., Roeder, K., 1977. Of genes and IQ. In: Devlin, B., Fienberg, S. Resnick, D., Roeder, K. (Eds.), Intelligence, Genes, and Success. Springer-Verlag, New York, pp. 45-70.

Derrida, B., Manrubia, S.C., Zanette, D.H., 2000. On the genealogy of a population of biparental individuals. Journal of Theoretical Biology 203, 303-315.

Derrida, B., Manrubia, S.C., Zanette, D.H., 1999. Statistical properties of genealogical trees. Physical Review Letters 82, 1987-1990.

Desmet, K., Le Breton, M., Ortuno-Ortin, I., Weber, S., 2009. The stability and breakup of nations: a quantitative analysis. Journal of Economic Growth 16, 183-213.

Dohmen, T., Falk, A., Huffman, D., Sunde, U., forthcoming. The Intergenerational Transmission of Risk and Trust Attitudes. Review of Economic Studies.

Einav, L., Yariv, L., 2006. What's in a surname? The effects of surname initials on academic success. Journal of Economic Perspectives 20, 175-188.

Fauré, R., Ribes, M., García, A., 2001. Diccionario de Apellidos Españoles. Espasa, Madrid.

Feldman, M.W., Otto, S.P., Christiansen, F.B., 2000. Genes, culture, and inequality. In Arrow, K., Bowles, S., Durlauf, S. (Eds.), Meritocracy and Economic Inequality. Princeton University Press, New Jersey, pp. 61-85.

Fryer Jr., R.G., Levitt, S.D., 2004. The causes and consequences of distinctively black names. Quarterly Journal of Economics 119 (3), 767-805.

Goldin, C., Shim, M., 2004. Making a name: women's surnames at marriage and beyond. Journal of Economic Perspectives 18 (2), 143-160.

Harris, J.R., 1998. The Nurture Assumption: Why Children Turn Out the Way They Do. The Free Press.

Holloway, S.M., Sofaer, J.A., 1992. Coefficients of relationship by isonomy among registrations for five common cancers in Scottish males. Journal of Epidemiology and Community Health 46, 368-372.

Jennings, M.K., Stoker, L., Bowers, J., 2001. Politics across generations: family transmission reexamined. Institute of Governmental Studies, University of California, Berkeley.

Jobling, M.A., Hurles, M.E., Tyler-Smith, C., 2004. Human Evolutionary Genetics. Origins, People \& Disease. Garland Science, New York.

Jobling, M.A., 2001. In the name of the father: surnames and genetics. Trends in Genetics 17 (6), 353-357.
Lasker, G.W., 1985. Surnames and Genetic Structure. Cambridge University Press. Legendre, P., Legendre, L., 1998. Numerical Ecology. Elsevier, New York.

Mantel, N., 1967. The detection of disease clustering and a generalized approach. Cancer Research 27, 209-220.

Mazumder, B., 2005. Fortunate sons: new estimates of intergenerational mobility in the United States using social security earnings data. The Review of Economics and Statistics 87 (2), 235-255.

Mulligan, C., 1997. Parental Priorities and Economic Inequality. University of Chicago Press, Chicago

Mulligan, C., 1999. Galton vs. human capital approaches to inheritance. Journal of Political Economy 107 (6), 184-224.

OECD, 2002. Trends in International Migration. Publications Service, Paris.

Pollak, R.A., 1978. Endogenous tastes in demand and welfare analysis. American Economic Review 68 (2), 374-379.

Rodriguez-Larralde, A. Gonzales-Marin, A., Scapoli, C., Barrai, I., 2003. The names of Spain: a study of the isonymy structure of Spain. American Journal of Physical Anthropology 121, 280-292.

Rowe, D., 1994. The limits of family influence: genes, experience and behavior. The Guilford Press, New York.

Salazar-Acha, J., 1991. Génesis y Evolución Histórica del Apellido en España. Real Academia Matritense de Her áldica y Genealogía, Madrid.

Simonson, I., Sela, A., 2011. On the heritability of consumer decision making: an exploratory approach for studying genetic effects on judgment and choice. Journal of Consumer Research 37 (6), 951-966.

Smouse, P.E., Long, J.C., Sokal, R.R., 1986. Multiple regression and correlation extensions of the mantel test of matrix correspondence. Systematic Zoology 35, 627-632.

Sokal, R.R., Rohlf, F.J., 1995. Biometry: The Principles and Practice of Statistics in Biological Research. W.H. Freeman and Company, New York.

Solon, Gary, 1992. Intergenerational income mobility in the United States. American Economic Review 82 (3), 393-408.

Stigler, G.J., Becker, G.S., 1977. De Gustibus non Est Disputandum. American Economic Review 67 (2), 76-90.

Waldkirch, A., Ng, S., Cox, D., 2004. Intergenerational linkages in consumption behavior. The Journal of Human Resources 39 (2), 355-381.

Wilhelm, M.O., Brown, E., Rooney, P.M., Steinberg, R., 2008. The intergenerational transmission of generosity. Journal of Public Economics 92, 2146-2156. 